\title{
THE ROLE OF THE ACCOMPANYING PIANIST IN THE VIOLIN PIECES AND THE PIANO COMPILED BY SELIM BELMJREN
}

Dalia Abdel-Hay BADIR *

Department of Performance, Faculty of Music Education, Helwan University, Egypt

\begin{abstract}
The instrumental and lyrical accompaniment plays an important role in enriching the fabric of melodies and determining the forms of harmony and coherence between musical instruments, and the piano is one of the most important accompanying instruments that can convey the beauty of thought and expression and are used to accompany food and various orchestral instruments, so the accompanying pianist needs full understanding. In his turn in the performance as the accompanying player is not just a supporter of the playing, but rather he is sometimes the leader of the artistic work, and the researcher saw that there are many difficulties that face the accompanying pianist when performing the accompaniment as it contains different musical techniques and requires expressive and performing skills and Also, the complete compatibility between the pianist and the other instrument that helps in producing the artistic work in the correct manner, and as the accompanying pieces have become included in the piano curricula of the BA stage in the Performance Department of the Faculty of Music Education, so the researcher considered that dealing with violin and violin pieces classified 2 by Salim Balmgrin (18-1951) Selim Palmgren (Selim Palmgren) with study, performance analysis and overcoming difficulties: its technique will help the accompanying pianist to perform it properly. True.

\section{Keywords}

Role, Accompanying, Pianist, The Violin Pieces, Selim Belmjren.
\end{abstract}

\section{Introduction:}

Music is a universal art that is listened to and played by people all over the world, which differs in its character and expressive style according to the place in which it was originated and in the style of composition stemming from composers over the generations, and this music has lived in continuous change during different ages as a result of the continuous attempts of Alongside leading composers, discovering new possibilities for music expression and artistic creation.

The instrumental and lyrical accompaniment plays an important role in enriching the texture of melodies and determining the forms of harmony and coherence between musical instruments. The accompaniment that can convey the beauty of thought and expression, whether it is playing solo or accompanying singing and various orchestral instruments, so the accompanying pianist needs a full understanding of his role in the performance as he is not only a supporter of the playing, but that he is sometimes the leader of the artistic work, and she saw The researcher said that there are many difficulties that face the accompanying pianist when performing the accompaniment. It also contains different musical techniques and requires expressive and performance skills, as well as the full compatibility between the pianist and the other instrument, which helps in correctly reproducing the artistic work.

Research problem:

\footnotetext{
* Corresponding author: info@music.helwan.edu.eg
} 
The accompanying pianist needs personal and technical skills in order to achieve the required level in the dialogue between himself and the soloist and perform properly and well, and since the accompanying pieces have become included in the piano curriculum for undergraduate students at the Faculty of Music Education, so the researcher decided to choose some violin and piano pieces by Finnish author Selim Balmagren is classified because it contains technical and expressive elements in addition to its attractive melodies and rhythms, and it is studied and analyzed with instructions that benefit the accompanying pianist to reach good performance.

The essential skills that a companion pianist must have:

First: Personal skills: -

- The accompanying pianist must be distinguished by the following:

1- Responding and merging with the individual machine in terms of agreement on the method of accompaniment, performance, speed, expression, and some instructions agreed upon between them.

2- Flexibility in performance so that he takes over the leadership of the work and is not just a follower of the soloist and a musician and a listener at the same time, and they cooperate with each other to focus on successfully producing the artistic work.

3- The vigilance of the accompanying solo player when performing something that was not agreed upon or the occurrence of a mistake, repetition or sudden acceleration in time, so the accompanying player must be alert and not be disturbed by this error, but rather complete the performance with the single instrument correctly.

4- Control the performance so that he is aware of the type of work, the type of instrument that accompanies it, the psychological state and the place in which he performs the performance and is more calm until this is reflected in the singer or the soloist.

Second: technical skills: -

1- Proficiency in initial reading, which is one of the important skills that must be available in the accompanying player to be able to accompany the compositions that he reads for the first time without stopping, and this requires the ability to play the piano and the flexibility of the movement of the fingers and has a distinguished degree of technique and is acquired through continuous and regular training.

2- Familiarity with the science of harmony helps the accompanying musician perform the spoils easily and enables him to know the stairs and the harmonic transformations by the composition, the type of texture, and the style of the era in which it is composed.

3- Mastering the technique of technique is one of the most important factors that must be available in the accompanying player, through training in the performance of all the techniques 
of the instrument and full control over the possibility of expression and the ability to overcome the difficulties that face him through continuous training.

4- The skill of improvisation, as it enables the accompanying player to create compositions with rhythmic variations that fit the melody of the piece, and also helps him to move from one maqam to another freely, and in the event of any mistake by the soloist, the accompanying player can improvise the melody until reaching the accompaniment again.

5- Filming the melody above or below the pitch, especially with the singer, to suit his vocal pitch, so the accompanying player must perform the piece on its original scale and photograph it on another level.

6- Understanding the best way to perform an expression on the piano instrument, and this is not limited to performing the expressions of intensity $(\mathrm{m}, 2)$, or fading (m, ppp, pp) with precision only, but also achieving a sound balance between him and the soloist and feeling the musical depth of the character of the single instrument .

The role of the pianist towards accompanying the solo instrument:

1- Intelligence in quickly getting acquainted with the specifications and characteristics of the author, discovering difficulties and trying to overcome them.

2- Self-confidence increases his ability to focus and perform correctly without errors, and thus this confidence is transmitted to the soloist.

3- Understand the primary role of the companion, which is the accompaniment of the solo instrument, so his performance should not overwhelm the melody of the soloist.

4- The ability to teamwork and cooperation to fully produce the artwork.

Violin Violin The violin instrument was called by several names, including Violin * in French, and Violino in Italian, and it occupies a great position among musical instruments throughout the ages, and is considered one of the smallest and most expressive string instruments as it can produce various and different sounds through The methods of playing it, whether using the bow or without it, and some believe that it expresses the thinnest feelings and feelings and also expresses anger and despair), which gives her supernatural power of expression and became the pioneer of instruments in the symphony orchestra, and despite the high position of the instrument around the world, it did not appear on it. Any change for several centuries The violin instrument has received the attention of many composers who have written for it many compositions, whether individually or in orchestral groups, or accompanied by other instruments such as Mozart, Beethoven, Schumann and other composers throughout the ages. research results:

After completing the theoretical and instrumental analysis of the research sample selected from 
the violin and piano pieces compiled $\vee \wedge$ by Salim Balmagren, which is fragment No. 1, 3, and 6 , the researcher reached the following results, which answer the research questions:

1- The first question: What is the manner of performing the accompaniment in Salim's compositions with violin and piano classified $\vee \wedge$ especially?

The researcher came up with a sound method with al-Magren in the compositions accompanying the piano and violin "The Research Sample" and was characterized by the following:

Singing melodies with simple rhythms.

For example, the absence of a guide defining the place of the piece.

- Change the keys frequently, for example, the syllable number $(r, 6)$.

- Using the pedal to enrich the melody.

A piano playing skill requires many expressive terms and expressive colors in different degrees.

- The contrast between the slowdown progress .rit and the progressive acceleration accel then return to the original speed. A tempo

Repetition of melodies with variation in accompaniment.

- The use of ornaments in many parts of the pieces

- The use of expressive long braces and short curly braces Slur.

2- The second question: What are the appropriate musical instructions to reach the good performance of the accompanying pianist in violin and piano compositions compiled سليم by Salim Balmagren?

After the structural and performance analysis of the pieces "the research sample, the researcher placed some musical instructions at the end of each piece to reach the level of good performance, which she summarizes as follows:

- Listen to the violin solo player to learn the melodic and rhythmic plan and the sense of the piece.

- The necessity of a complete agreement between the violinist and the pianist accompanying the correct start, which requires that there be an agreed upon sign between them.

- To be attentive to the performance of the violin player and to follow musical expressions, whether a faint performance in all its degrees, PPP, PP, or strong performance in different degrees $\mathrm{ff}, \mathrm{mf}$, and the gradation between them and follow the speed and slowdown and wait for the starting signal from the violinist to return to the original speed. Flexibility in performance and simulation of a violin player in showing all his musical expressions.

Commitment to the numbering suggested by the researcher. 
Pay attention to changing the clefs.

- Interpretation of all the colors and terminology of the expression with different degrees of touch and flexibility in producing expressions in a way that does not overwhelm the performance of the violinist.

Wait until the sound fades when the prolongation sign appears. This requires upfront spending among players on the start signal and marking time.

The researcher also developed exercises to facilitate performance, such as:

1- Performing exercise Left-handed jumping Maze No. 20.

2- Exercise to perform the Achikatora bauble No. 20.

3- The researcher placed photographs showing the position of the hands in performing a musical interference, a number $r$.

3- The third question: What are the methods of developing musical abilities and skills of the accompanying pianist? The researcher found methods of developing the musical abilities and skills of the accompanying pianist, which are as follows:

1- He shall have a great technical and expressive ability that enables him to perform the accompaniment. Be fluent in Sight Reading.

2- To be fully aware of the capabilities of the violin machine while accompanying it.

3- The flexibility of the accompanying player to achieve balance with the soloist.

4- Development of the skill of instantaneous reaction with the soloist.

5- Familiarity with the rules of harmony, knowledge of ladders and hormonal transfers.

6- Proficiency in performing some of the technical forms that the researcher was exposed to during the analysis, such as:

Harmonized triple and quadruple damage technique.

Octave technic

Arpegesis.

The jump of all kinds.

- Aldawas

- Arpeggio ornament.

Small arcs.

- Playing choppy.

- Apogatura ornament.

- Accatora ornament.

Recommendations:

The researcher recommends the following: 
1- Inclusion of Salim's compositions in the college library, especially the accompaniment works, in order to allow learners to choose them within the curriculum for playing the piano due to its high playing techniques that help in preparing the accompanying pianist

2- Providing audio recordings of accompanying compositions for many composers in the College Listening Library to give the student an opportunity to hear them.

3- Organizing musical seminars that include explaining and listening to the works of the author "Salim Bel-Mujren" so that college students get to know them and introduce their playing.

\section{References:}

1- Alfred Einstein: Music in the Romantic Age, translated by Dr. Ahmed Hamdi Mahmoud Hussein and publishing, Cairo, 18 AD. Fawzi, Egyptian General Book Authority, authoring house

2- Awatef Abd al-Karim: The Romantic Age, Memoirs of the History of the Fourth Division, Faculty of Music Education, Helwan University, 19 AD.

3- Mahmoud Ahmad El-Hefny: The Science of Musical Instruments, Egyptian General Book Authority, Cairo, 1971

4- Apel, Willi: Harvard Dictionary of music , fourth Edition, Harvard University Press, London, 1971.

5- $\quad$ Ardley, Neil: Music an illustrated Encyclopedia, Hamlyn Publishing, London, 1986.

6- $\quad$ Baker, Richard: The Hamlyn Illustrated Encyclopedia of music, the Hamlyn Publishing group, Limited, London, 1990.

7- Bloom, Eric: Groves Dictionary of music and musicians, vol. 1, London, 1954.

8- Kuehn, Jacquelyn: The Basics of Accompaniment, Clvier Magazine, vol. 34, No.9, 1995

9- Latham, Alison: The Oxford Companion to music, Publish in Oxford Univercity Press. Inc. New York. 2002.

10- Michael, Kennedy and Bourne Kennedy: The concise Oxford Dictionary Of Music, Fifth Edition, Oxford University Press, 2007.

11- Philipp, H, Lillie: Piano Technique, Dover Publications. Inc., New York 1980.

12- Sadie, Stanley: The New Grove Dictionary of music and musicians, vol.14. Macmillan publishers limited, 2001.

13- Schelling, Ernst and Others: Oxford Piano Course, Oxford Univercity Press, Inc, New York, 1988.

14- Slonimsky, Nicolas: Baker's Biographical Dictionary of musicians, Seventh edition, Macmillan, New York, 1998. 
15- https://www.allmusic.com/artist/johann-christian-bach-mn0002132738/ compositions

16- https://www.classicfm.com/discovermusic/instruments/violin/features/bestviolinpieces/

17- https://en.wikipedia.org/wiki/Selim Palmgren

18- https://www.allmusic.com/artist/selim-palmgrenmn0001171189/biography

19- https://ylioppilasmatrikkeli.helsinki.fi/18531899/henkilo.php?id=24778

20- https://www.britannica.com/biography/Selim-Palmgren

21- https://www.wrightmusic.net/pdfs/selim-palmgren.pdf

22- https://imslp.org/wiki/List_ of works by Selim Palmgren

23- https://en.wikipedia.org/wiki/Accompaniment

24- https://www.britannica.com/art/violin

25- Amira Muhammad HALLOUL, THE INNOVATION OF 2D ART CANVASES BASED ON RECYCLING FOR THE DEVELOPMENT OF CREATIVE THINKING AMONG THE STUDENTS OF THE FACULTIES OF ART, International Journal of Education and Learning Research, Vol. 3, No. 1, 2020, pp. 22-28.

Received: September 25, 2020

Accepted: November 30, 2020 